\title{
Modeling and Analysis of Integrated Bathymetric and Geodetic Data for Inventory Surveys of Mining Water Reservoirs
}

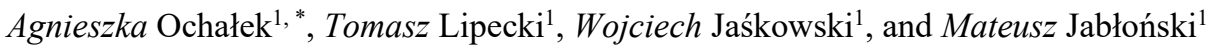 \\ ${ }^{1}$ AGH University of Science and Technology, Faculty of Mining Surveying and Environmental \\ Engineering, A. Mickiewicza Av. 30, 30-059 Krakow, Poland
}

\begin{abstract}
The significant part of the hydrography is bathymetry, which is the empirical part of it. Bathymetry is the study of underwater depth of waterways and reservoirs, and graphic presentation of measured data in form of bathymetric maps, cross-sections and three-dimensional bottom models. The bathymetric measurements are based on using Global Positioning System and devices for hydrographic measurements - an echo sounder and a side sonar scanner. In this research authors focused on introducing the case of obtaining and processing the bathymetrical data, building numerical bottom models of two post-mining reclaimed water reservoirs: Dwudniaki Lake in Wierzchosławice and flooded quarry in Zabierzów. The report includes also analysing data from still operating mining water reservoirs located in Poland to depict how bathymetry can be used in mining industry. The significant issue is an integration of bathymetrical data and geodetic data from tachymetry, terrestrial laser scanning measurements. Key words bathymetry, inventory, reclamation.
\end{abstract}

\section{Introduction}

Exploitation of natural deposits and subsequent processing of acquired resources lead to noticeable changes not only in relief but also in water balances of mining terrains. Mining activity is often causes arising of water reservoirs, which should be inventoried both during the exploitation and after finishing the mining output.

Inventory surveys of operating mining water reservoirs, which formation is related to mining exploitation, is necessary at every stage of the mining output process. At the stage of preparation for the exploitation, measurements are based on recognizing the bottom of the reservoir and its underwater natural resources. There are documentation such as: plans for the development of the deposit, detailed technical projects of the stages of exploitation and land development plans prepared, as well as initial plans of land development after the completion of mining output [1]. During the exploitation, the bathymetrical measurements are used to make whole the geological and mining documentation. All the records are obligatory due to Polish geological and mining law and Polish norms. Except for it, hydroacoustic surveys also provide compilations of the quantity of extracted and left underwater deposits.

\footnotetext{
Corresponding author: ochalek@agh.edu.pl
} 
According to Polish Geological and Mining Law, in case of in case of liquidation of a mine, an entrepreneur is obliged to take the necessary actions to protect the environment and to reclaim land after mining activity. The water direction of land reclamation gives new opportunities of enriching natural environment by rising the landscape values or increasing the biodiversity $[2,3]$. In this case the main purpose of researches might be determining a better direction of reclamation of post-mining reservoir and more advantageous way of its usage, for example: water and recreation direction of reclamation - post-mining reservoir as a bathing place or a fishery for anglers [4]. There are many various parameters such as: inclination of underwater coasts, structure and slitting or vegetation caver which should be taken into account during the inventory surveys of water reservoirs due to land reclamation.

The basis of the safe usage of water reservoirs influenced by mining activity is their accurate morphometric identification. Obtaining information about depth or bottom shapes of water reservoirs or identification and verification of underwater objects are complex processes which require comprehensive elaboration of collected data [5].

\section{Technology of bathymetric measurements}

In practice inventory of inland water reservoirs is connected with bathymetric measurements on the research area. Nowadays, possibilities of carrying out the hydroacustic surveys are constantly enhancing and becoming more and more advanced. Studies of lakes morphometry require an accurate representation of their bottom geometry in the form of a bathymetrical map or more often a three-dimensional bottom model [6].

Contemporary hydrographic works involves a lot of modern and innovative electronic equipment. The rudimentary hydroacoustic device which obtains information about the depth of inventoried water reservoir is a single beam echo sounder (SBES) equipped with a converter that produces and sends one single beam with a vertical acoustic axis (Fig. 1).

The sent impulse bounces off the bottom or obstacles and returns after some time to the device. This time depends on the depth and the speed of sound propagation in water. At the same time, the velocity is connected with density of water, so its temperature and salinity. The sound propagation in the freshwater tank is approximately $1500 \mathrm{~m} / \mathrm{s}$. Knowing the velocity and the return time of acoustic signal, it is easy to determine the depth of the reservoir.

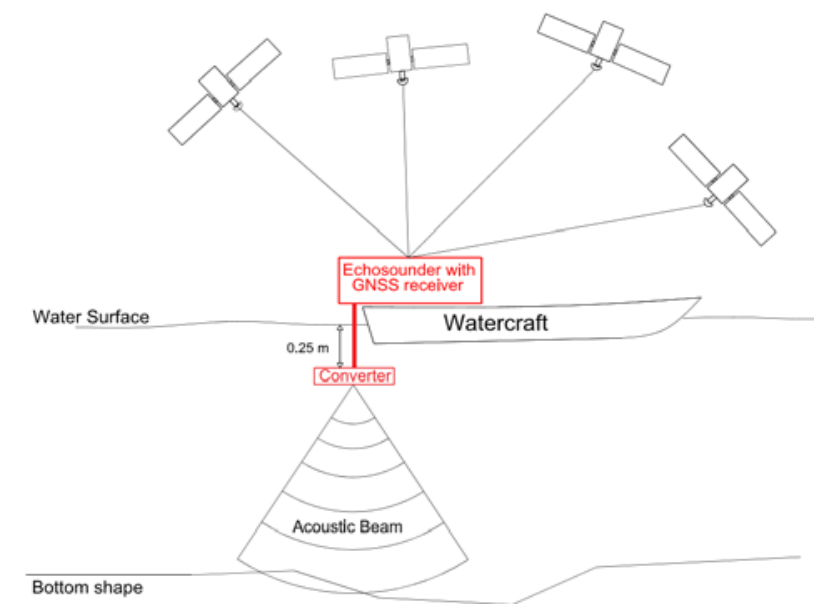

Fig. 1. Single Beam Echo Sounder - operation rules

Echo sounders used on small watercrafts used a beam width of more than $50^{\circ}$. Such beam with provides a relatively large space of research and gives more information about 
underwater environment. However, it offers less angular resolution and surveys at lower depths. Using narrower beams (for example $10^{\circ}$ ) allows a deeper penetration, but converters with narrow cone angle need stabilization and are usually installed in research echo sounders. The cone wide angle converters work better in freshwater reservoirs, while the narrow cone version is suitable for both types - freshwater and salt water reservoirs.

Technology development contributed to produce multi beam echo sounder (MBES) [7]. This is an innovative solution that combines the advantages of an echo sounder and a sonar. This device, during measurement, sends multiple independent acoustic beams at different angles, but at the same frequency. The same amount of independent impulses is received and give the information about depth and the shape of the bottom surface. In comparison to SBES, MBES has a lot of advantages [8]. For sure, it is a device which can be easily used at medium and large depths or to measure reservoirs with large surfaces. All the obtained data might be used not only to illustrate the sonar bottom configuration, but also to identify underwater objects [9].

\section{Research area and methodology of measurements}

There were two measurement cycles on two water reservoirs - Dwudniaki Lake in Wierzchosławice and "Mały Zakrzówek" in Zabierzów carried out in 2016 and 2017 in order to collect the adequate amount of bathymetric and geodetic data for further analysis. In this report the data were also acquired from the measurements at still operating open-pit mine Kunice IV, where deposits are extracted from underwater. All the research areas are in southern Poland and are shown in red colour at the Figure 2.

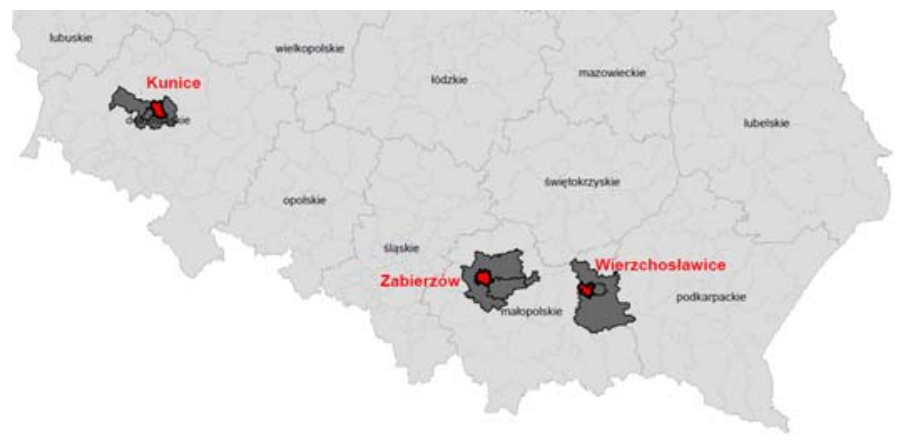

Fig. 2. Research area - localization of inventoried water reservoirs

The integrated bathymetric system based on the watercraft, multi beam echo sounder Lowrence Elite-7 CHIRP and DGPS receiver built-in it the device was used to hydroacoustic measuremens at two above mantioned water reservoirs. The echosounder - Lowrence Elite-7 CHIRP combines two technologies: the classic echo sounder and CHIRP sonar (Compressed High Intensity Radiated Pulse) [7].

Asopposed to simple 2D sonar that sends single frequency, devices with CHIRP transmit range beams in different frequencies. Every returned frequency is individually interpreted. Sweeping range of frequencies guarantees a much wider information and the CHIRP sonar provides a higher resolution and legibility of recieived data [10].

There were not only bathymetric measurements carried out during the inventory surveys of the flooded quarry in Zabierzów. Additionally, there were some geodetic works made such as surveys to establish control points on the research area and terrestrial laser scanning in order to visualize the walls of the former excavation. There were Leica ScanStation C10 laser scanner used to make the inventory. Static measurements and tachymetry were performed 
with integrated Topcon HiPer Pro receivers and Topcon OS-103 tachymeters. The geodetic works allowed to register scans in global coordinate system (PL-2000, EPSG 2178). Moreover, for the determining the accuracy of the echosounder, an additional direct measurements of deptha at three profiles were carried out by using line with a centimeter scale and a weight at the end.

It is worth mentioning that there were the route profile project in *.gpx file format created before the bathymetric surveys. Next it was imported to echo sounder and used during the measurements. It has enabled to track the route and an efficient navigation of watercraft. However, it sould be emphasized that the projected survey profiles do not always fulfil their purpose, especially on operating open-pit mines where floating conveyors and mining equipments are in constant move. Measurements conducted in that conditions should be monitored on a regular basis, avoiding obstacles.

\section{Processing of the data}

In the geodetic aspect the bathymetric measurements are aimed to create maps, crosssections, and a DTM of the bottom, including the positioning of this model in a global reference system. The data acquired from hydroacoustic surveys has to allow for the accurate reproduction of invetoried reservoir's details. Therefore, the information about the spatial coordinates of watercraft's localization (or more specified the echo sounder's converter) and the depth information are needed. Innovative devices also provide information about the frequency udef for survey $[\mathrm{kHz}]$, water temperature $\left[{ }^{\circ} \mathrm{C}\right]$ and velocity of the watercraft $[\mathrm{kn}]$. All the data is displayed in the echosounder's screen and then collected in the database, which should be properly sorted and veryfied afther the survey. The significant aspect of database management is the validation of measured points which would be taken into account during the analysis of the bottom shape of water reservoirs. The next issue is the corecction of definited depth due to the immersion of echo sounder's converter (Fig. 1).
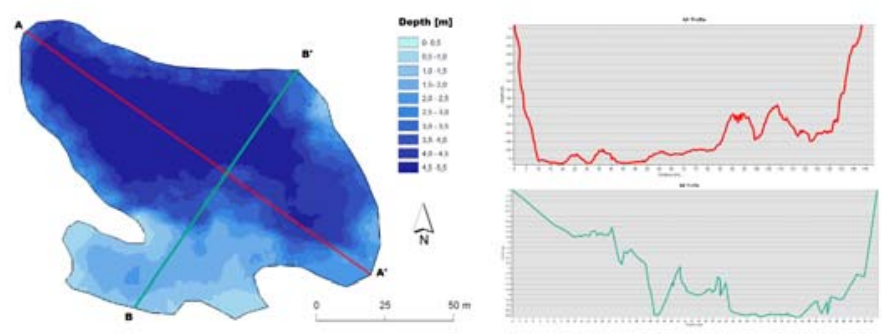

Fig. 3. The morphometric characteristic of flooded quarry „Mały Zakrzówek”

Table 1. Morphometric characteristics of inventoried reservoirs

\begin{tabular}{|l|c|c|}
\hline \multirow{2}{*}{\begin{tabular}{c}
\multirow{2}{*}{$\begin{array}{c}\text { Morphometric } \\
\text { characteristic }\end{array}$} \\
\cline { 2 - 3 }
\end{tabular}} & \multicolumn{2}{|c|}{ Reservoir's name } \\
\hline Area $F_{0},\left[\mathrm{~m}^{2}\right]$ & 200800 & „Mały Zakrzówek” \\
\hline Lenght $L,[\mathrm{~m}]$ & 676 & 9200 \\
\hline Mean width $B_{\text {sr, }}[\mathrm{m}]$ & 297 & 148 \\
\hline Max width $B_{\text {maks, }}[\mathrm{m}]$ & 425 & 62 \\
\hline Mean depth $h_{\text {sr, }}[\mathrm{m}]$ & 1,20 & 70 \\
\hline Max depth $h_{\text {max }},[\mathrm{m}]$ & 3,65 & 2,8 \\
\hline Volume $V_{0},\left[\mathrm{~m}^{3}\right]$ & 243500 & 5,5 \\
\hline Number of depth points & 5336 & 25650 \\
\hline
\end{tabular}


Such structured and comprehensive database can be used in GIS software, which can give a lot of possibilities of presenting the result of researches. An example of detailed vizualization in the form of a bathymetric plan and a cross section through the longest profile of the reservoir which describe the shape of the bottom of the inventoried lake was preseted (Fig. 3). Commonly used determining of reservoirs' morphometric characteristic has been replaced by simple operations in GIS environment, assuming that a the inventoried reservoir is represented by the digital data model consisting of a polygonal contour and a layer connected with depth (the raster model). Obtained morphometric characteristics of the invetoried lakes are shown in Table 1.

Bathymetric data is often presented as traditional (paper or vector) two-dimensional maps. However, nowadays this way of presenting to many clients is no longer satisfactory, geovizualization and three-dimensional models of terrain and surface are essential. One of the effective methods of representing and analyzing surfaces is the Digital Terrain Models (DTM). DTM can be represented for example by Triangulated Irregular Network (TIN), which is an irregular grid of triangles used to present complicated and varied surfaces. The GPS positioning and echo-sounding measurements allows the use of a third dimension in the processing of the obtained bathymetric data. The process of creating DTM and 3D visualization of two inventoryed water reservoirs were carried out in the ESRI ArcMap 10.2 program (Fig. 4).
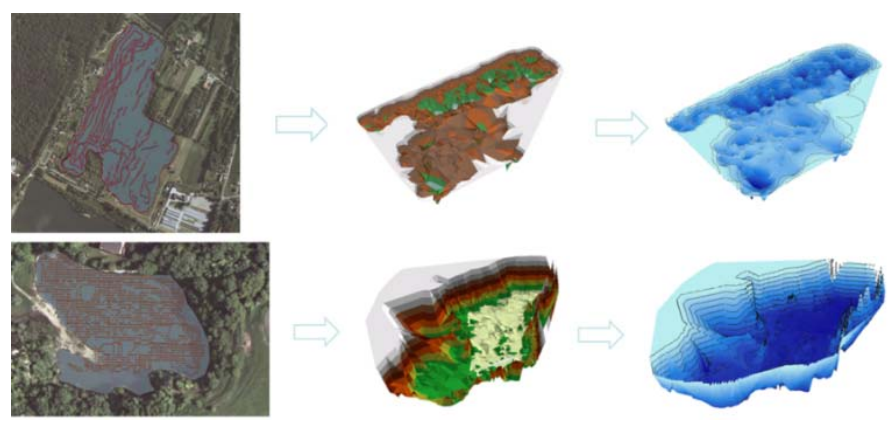

Fig. 4. Process of DTM formation and 3D vizualization of the bottom surface of the water reservoir in ArcMap

In order to analyze the conducted hydroacoustic survey in comparison with the direct depth measurements by using line with a centimeter scale and a weight at the end, surveys were made along three projected profiles through the reservoir. Measurement lines were signaled by a specially prepared rope, which was marked at every distance of $1 \mathrm{~m}$. The beginnings and ends of the projected profiles were measured by the tachymetr. On each profile, the depth was directly determined every 2 meters by using a measuring line and tied stone and its end. Simultaneously, the value of the depth, which was displayed on the echo sounder's screen, was written down. The pairwise observation method was used to determine the accuracy of the measurements. The results of which are shown in Table 2. Data analysis showed an average error of both measuring methods about $0.14 \mathrm{~m}$.

Table 2. Analysis of the measurements by the method of pair of observations

\begin{tabular}{|l|c|c|}
\hline \multicolumn{1}{|c|}{ Profile } & Mean difference error $\boldsymbol{d}_{\text {sr }}[\mathbf{c m}]$ & Mean unit error $\boldsymbol{m}_{\mathbf{0}}[\mathbf{c m}]$ \\
\hline $\mathrm{AA}^{\prime}$ & 12,5 & 8,9 \\
\hline $\mathrm{BB}^{\prime}$ & 20,2 & 14,3 \\
\hline $\mathrm{CC}^{\prime}$ & 25,9 & 18,3 \\
\hline Mean error & 19,5 & 13,8 \\
\hline
\end{tabular}




\section{Interpretation of bathymetric and geodetic data by the example of lake Dwudniaki and Maly Zakrzowek}

The inventory surveys of Dwudinaki Lake located in Wierzchosławice were divided in two parts: the first one (shown in the Figure 5 in green was made in May 2016) and the second one (marked in violet in August 2016). The first hydroacoustic survey was made with a good visibility of the bottom of the reservoir, and the second was already done with a large amount of plants hovering at the surface of the water or in the water. After validating and sorting the obtained database, it turned out that a lot of measured depth points were discarded because of the wrong depth value (for example zero value). Figure 5 also depicts the comparison of the flow path of the measuring unit and the number of points that, after validation, were suitable for use during the reservoir's bottom interpolation. Nevertheless, the received data was sufficient enough to carry out the entire process of acquiring, introducing, managing, analyzing and visualizing the bathymetric data.
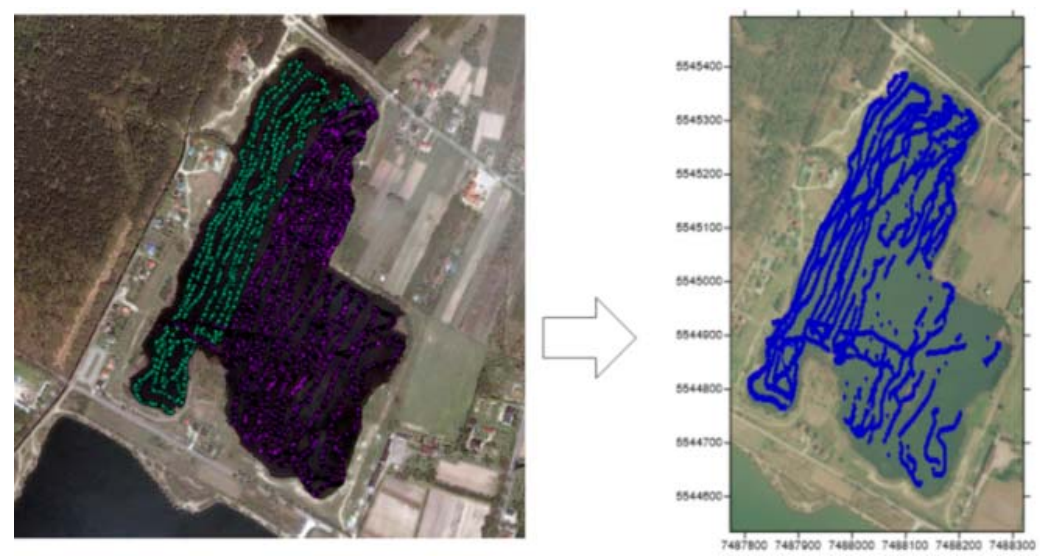

Fig. 5. Validation of depth points taken into account during analyzing the bottom shape of the Dwudniaki water reservoir
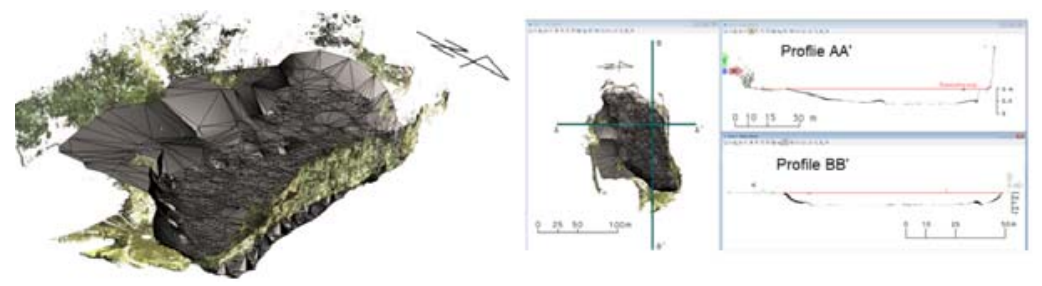

Fig. 6. Integration of bathymetric and geodetic data

For accurate inventory of the water reservoir and its surroundings, all obtained measured data should be combined. An integration of acquired information from bathymetric measurements (the shape of the bottom) and geodetic surveys (terrestrial laser scanning visualization of the excavationn's walls, static GNSS measurements and tachymetry) consisted of putting every kind of data into the same reference global system (PL-2000, zone 7, EPSG 2178). Therefore, the data integration problem was mainly focused on transforming the depths so they correspond the elevation of geodetic measured points. The combination of researches carried out in two environments (on land and water) allowed to create the comprehensive and accurate model of the whole excavation and to make cross sections (Fig. 6). 


\section{Processing of bathymetric data acquired from measurements at operating open pit mine Kunice IV}

The data obtained from the bathymetric measurements at the Kunice IV open-pit mine at different times allowed to visualize the progress of the underwater mine exploitation. Figure 7 depicts the visualization of bathymetric surveys at all measuring cycels, so all recived bathymetric points and the DTM created based on them. The deposits extraction proceeds in the north-east direction.
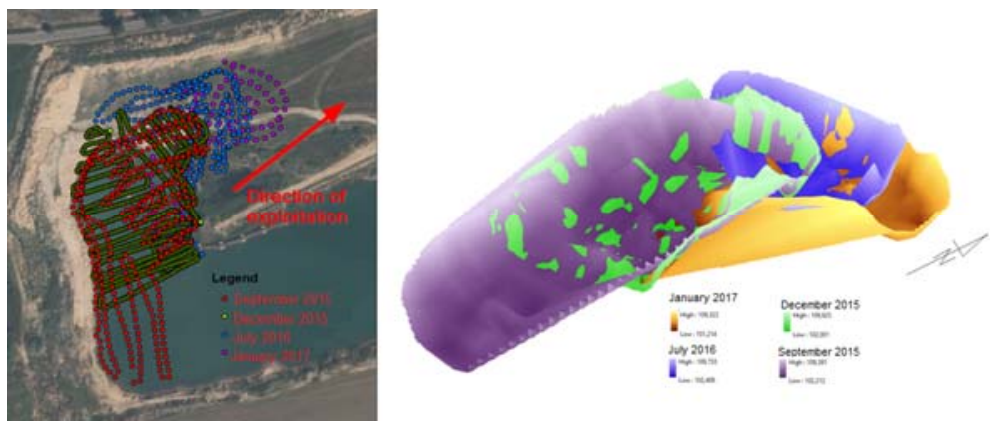

Fig. 7. The visualization of bathymetric surveys at all measuring cycels
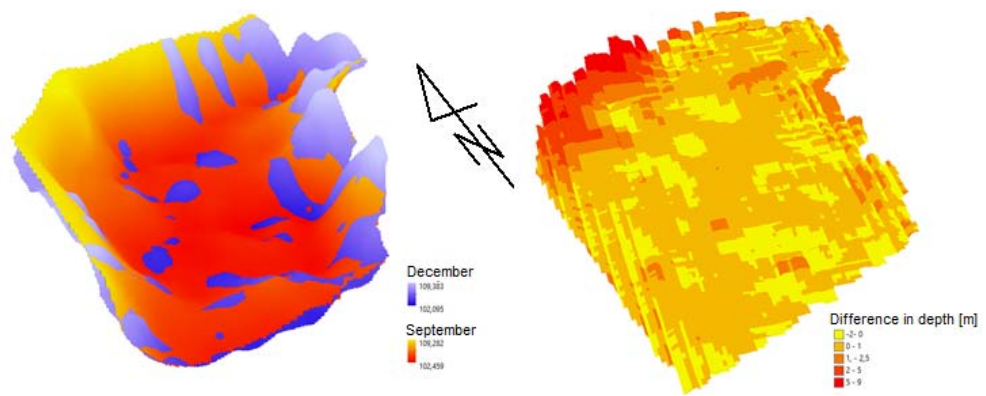

Fig. 81. DTM created from data obtained from measurements made by using SonarMite echosounder in September (orange colour) applied to DTM created from data acquired from surveys made by using AIRMAR B164 echosounder in December (blue colour) and the depth difference map

At the next stage of the study, the attention focused on the part of the water reservoir where measurements were made twice - in September 2015 by using SonarMite echo sounder and December 2015 with AIRMAR B164 echo sounder. In order to more accurate analysis of the received data, DTMs in raster format were created. Before this process, it was necessary to determine the appropriate area for the analysis, which included the same range of measurements performed at both dates. It allowed to make raster analysis in selected environment. Additionaly, apart from classical cross sections through DTMs, the method of comparison of the measured depths is shown in the Figure 8. There is the imposition of the models on each other - the orange shades indicate surveys in December, the blue shades in September - and the depth difference map showed. The minus results indicate a greater depth for the September's model. The maximum difference in height was $8.71 \mathrm{~m}$, while the average was $0.55 \mathrm{~m}$. The differences were mainly due to the fact of carrying out mining works. What is more, the volume of the two models was also calculated. The calculated difference in volume of the two models may determine the amount of excavated deposits in the analyzed area during 3 months, it's about $7860 \mathrm{~m}^{3}$. 


\section{Conclusions}

Acquiring information about depth or bottom shapes of water reservoirs or identification and verification of underwater objects are complex processes which require comprehensive elaboration of collected data. The more interdisciplinary character of research is, the more effective cooperation between scientists and engineers from different fields is needed. Modern measuring techniques and development of GIS systems bring new opportunities for data processing. Bathymetric measurements in the mining industry are mainly used to determine the change of bottom shape of water reservoirs due to exploitation, its speed and quantity of extracted deposits. The inventory of post-mining reservoirs in order to determine the direction of their reclamation and its subsequent use is also a significant issue. More often, bathymetric data is presented in the form of three dimensional models and then used in designing and vizualizing reclamation.

The researches showed that the accuracy of the bathymetric measurement depends on many factors, and the measurement noises. These are mainly the result of the occurrence of underwater vegetation, changes in water density or the presence of fish, significantly disturb the process of obtaining and processing the data. The integration of geodetic and bathymetric data is a complex problem that requires detailed elaboration of collected data. However, it allows better visualization of measurement data.

\section{Acknowledgements}

Bathymetrical data from open pit mining Kunice IV obtained from mine surveyor - eng. Piotr Szajt. Article was developed in the framework of the AGH statutory no 11.11.150.195.

\section{References}

1. E. Gurzęda, Raport oddziaływania na środowisko projektowanej eksploatacji kruszywa naturalnego ze złoża , WITOWĄŻ I” (Gdynia, 2009)

2. K. Różkowski, K. Polak, M. Cała, Wybrane problemy zwiąane z rekultywacja wyrobisk w kierunku wodnym (Górnictwo i Geoinżynieria, 34/4, 2014)

3. K. Nazan, Reclamation of Degraded Landscapes due to Opencast Mining (Advances in Landscape Architecture, InTech, 2013)

4. D. Madusiok, Analysis of the possibilities for reclamation after aggregate exploutation in the Cracow's quarry of Brzegi by using remote sensing and geoinformatics (Geoinformatica Polonica, nr 15, Kraków, 2016)

5. R. Chesnaux, M. Llambert, J. Walter., U. Fillastre, M. Hay, M.A. Rouleau, R. Daigneault, A. Moisan, D. Germaneau, Building a geodatabase for mapping hydrogeological features and $3 D$ modeling of ground water systems: Application to the Saguenay-Lac-St.-Jean region (Computers \& Geosciences 37 (11), p. 1870, 2011)

6. B. Pączek, Współczesne Metody prowadzenia prac hydrograficznych (Przegląd hydrograficzny, No. 1, Gdynia, 2016)

7. Y. Kim, N. Koo, M. Riedel, H. Namgoong, J. Lee, S. Cheong, Y. Joo, D. Yoo, J. Chun, H. Lee, A case study on swell correction of Chirp sub-bottom profiler (SBP) data using multi-beam echo sounder (MPES) data (Journal of Applied Geophysics, vol. 145)

8. D.G. Simons, M. Snellen, A Bayesian approach to seafloor classification using multibeam echo-sounder backscatter data (Applied Acoustisc, vol. 70, pp. 1258-1268)

9. S. Innangi, A. Bonanno, R Tonielli, F. Gerlotto, M. Innangi, High resolutron 3-D shapes of fish schools: A new method to use the water column bachscatter from hydrographic MultiBeam EchoSounders (Applied Acoustics, vol. 111)

10. R.A. Altes, Wide-band, proportional-bandwidth Wigner-Ville analysis (IEEE Transactions on Acoustics, Speech and Signal Processing, vol. 38, pp. 1005-1012) 